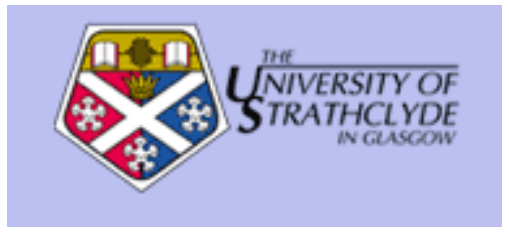

Hunter, Simon C. and Boyle, James and Warden, David (2007) Perceptions and correlates of peer-victimization and bullying. British Journal of Educational Psychology, 77 (4). pp. 797-810. ISSN 0007-0998

http://strathprints.strath.ac.uk/25688/

Strathprints is designed to allow users to access the research output of the University of Strathclyde. Copyright (C) and Moral Rights for the papers on this site are retained by the individual authors and/or other copyright owners. You may not engage in further distribution of the material for any profitmaking activities or any commercial gain. You may freely distribute both the url (http://strathprints.strath.ac.uk) and the content of this paper for research or study, educational, or not-for-profit purposes without prior permission or charge. You may freely distribute the url (http://strathprints.strath.ac.uk) of the Strathprints website.

Any correspondence concerning this service should be sent to The Strathprints Administrator: eprints@cis.strath.ac.uk 


\title{
Perceptions and correlates of peer-victimization and bullying
}

\author{
Simon C. Hunter*, James M. E. Boyle and David Warden \\ University of Strathclyde, UK
}

\begin{abstract}
Background. The experiences of peer-victimization and bullying are often treated empirically as though they are conceptually indistinct. Both involve repeated aggression, but definitions of bullying additionally emphasize the importance of aggressor intent and imbalance of power between the aggressor and the victim (Olweus, 1978; Whitney \& Smith, 1993).
\end{abstract}

Aims. The present study aimed to examine the extent to which peer-victimization and bullying are empirically similar.

Sample. The sample comprised I,429 pupils ( $50.2 \%$ male) aged between 8 and I3 years attending mainstream Scottish schools.

Methods. Self-report questionnaire assessing peer-victimization and bullying, coping strategy use (WCCL: Hunter, 2000), situational appraisal and depressive symptomatology (Birleson, 1981).

Results. Almost one-third (30.7\%) of pupils reported experiencing peer-victimization, and of these $38.1 \%$ (II.7\% of whole sample) were categorized as victims of bullying. Victims of bullying perceived higher levels of threat and lower levels of perceived control. They also reported using more Wishful Thinking and Social Support coping strategies, but did not differ on Problem Focused coping. Bullied pupils also reported higher levels of depressive symptomatology.

Conclusions. Peer-victimization and bullying appear to be qualitatively different experiences for children and adolescents, with bullying being the more serious phenomenon.

In the present study, we have two related aims. First, to discover the extent to which being bullied and experiencing repeated aggressive attacks (i.e. peer-victimization) are, from young people's perspectives, similar. To achieve this, we examine children's perceptions of (a) their aggressor's intent and (b) the presence of a power imbalance between themselves and their aggressor. Second, we aim to examine whether bullying and peervictimization are experientially similar, by examining their associations with the cognitive appraisals, use of coping strategies and psychological adjustment of victims. 
To what extent are bullying and peer-victimization conceptually similar? Bullying involves verbal, indirect and direct aggression (e.g. Ahmad \& Smith, 1994; Crick \& Grotpeter, 1995; Olweus, 1978), and is conceptualized as aggression which is repeated, where the aggressor intends to cause harm or distress, and in which there exists an imbalance of power between bully and victim (Naylor, Cowie, Cossin, de Bettencourt, \& Lemme, 2006; Whitney \& Smith, 1993). Peer-victimization, in contrast, is used to refer to a form of peer abuse in which a child is frequently the target of peer aggression (Kochenderfer \& Ladd, 1996, p. 1305). Hence, bullying is a special case of peer-victimization, since the latter does not explicitly include the issues of power imbalance and intent included in the definition of bullying. However, given that peervictimization is a recurring aggressive act with well-documented negative effects, it is appealing to assume that victims experience difficulty responding effectively and that aggressors are not acting with positive or benign intent. This would imply that peervictimization is, in the real world, simply a different name for bullying and that peervictimization in its purest definitional sense does not exist. Indeed, researchers already use the terms interchangeably by measuring peer-victimization but discussing results in terms of bullying (e.g. Champion, Vernberg, \& Shipman, 2003).

Whether such a conclusion can be drawn is a pertinent research question to ask, as it influences our interpretation of the existing research literature. If young people always attribute intent and a power imbalance within peer-victimization contexts, then both literatures (bullying and peer-victimization) can and should be treated as one. Conversely, if young people do not always make such attributions, then conclusions which can be drawn from the respective literatures may not be the same. Specifically, one (presumably bullying, see below) may be a harsher experience than the other and may require different or more intensive intervention. For example, if attributions of power imbalance are salient and important when distinguishing between the outcomes of bullied and victimized children, then these attributions may form the basis of intervention. This relates to research examining dominance hierarchies (e.g. Hawker \& Boulton, 2000a; Pellegrini \& Long, 2002), which suggests that classes or schools where there are high levels of bullying need to focus on the power dynamics operating within the pupil population. In contrast, intervention may be based more on a social skills training model (DeRosier \& Marcus, 2005; Nangle, Erdley, Carpenter, \& Newman, 2002) where high levels of peer-victimization (rather than bullying) occur as, potentially, the salient causal factors are more related to individual socio-cognitive deficits than group level dynamics. These are, of course, speculative suggestions and should we discover differences in the experiences of bullied and peer-victimized pupils, research would be required to clarify the distinguishing characteristics of these two phenomena, both in terms of individual level variables and group level dynamics.

Thus, the first aim of this study was to examine the extent to which being bullied and experiencing repeated acts of aggression are overlapping or identical.

\section{Are bullying and peer-victimization experientially similar?}

If victims of peer-victimization do not report aggressor intent and a power imbalance, it becomes important to establish whether this difference is associated with other aspects of students' experiences. We aimed to identify and discriminate between pupils who are experiencing peer-victimization and those who were bullied in terms of (a) their cognitive appraisal of the situation; (b) their use of coping strategies and (c) the extent to which they reported experiencing symptoms of depression. If members of these two 
putative groups differ only according to whether they perceive intent and imbalance of power, but not on pertinent perceptual and behavioural indices, then this may indicate that the two are conceptually distinct, yet indistinguishable in vivo. However, there are a number of reasons to believe that bullying is a more serious problem than peervictimization, based on the additional definitional constraints related to bullying.

Numerous studies have indicated that levels of depressive symptomatology are affected when children and adolescents are victims of peer-victimization or bullying. Hawker and Boulton (2000b), in a meta-analysis of 22 studies examining the effects of peer-victimization (which included being bullied), reported that the largest effect sizes were for depression (mean effect size $r=.29$ when avoiding shared method variance; $r=.45$ when not avoiding shared method variance), the lowest for anxiety (mean effect size $r=.21$ when avoiding shared method variance; $r=.25$ when not avoiding shared method variance), with loneliness and self-esteem lying between the two. Studies carried out since Hawker \& Boulton's meta-analysis have continued to support the argument that depression is a central problem associated with victimization. For example, Bond, Carlin, Thomas, Rubin, and Patton (2001) found that peer-victimization among Year 8 students predicted clinical levels of depression 1 year later and that this effect was stronger for girls than for boys. Kumpulianen and Räsänen (2000) also reported long-term effects, finding that children bullied at 8 years of age had significantly higher levels of parent- and teacher-rated depression at the age of 15 years than children not bullied at 8 years of age. Seals and Young (2003) report that adolescent victims of bullying in the US had significantly higher levels of depressive symptomatology than uninvolved peers, while among adolescent Norwegian students, Solberg and Olweus (2003) found a strong, positive correlation between both the frequency and the duration of bullying episodes and levels of depression.

It is because depressive symptoms appear to be particularly associated with the experience of repeated peer-aggression (whether peer-victimization or bullying) that we decided to investigate whether bullied pupils and those experiencing peer-victimization differed in their levels of depressive symptomatology. Hilsman and Garber (1995) report that young people who have a negative explanatory style are at risk of sustained negative affect when faced with negative stressors: the attribution of intent and power imbalance when victimized may reflect aspects of negative explanatory style, leading to increased depression for self-reported victims of bullying when compared with students selfreporting peer-victimization. Furthermore, both pessimism and self-rated social competence are related to depression in young people (Lewinsohn et al., 1994) and it is reasonable to expect that such cognitive variables are also associated with attributions of power imbalance since a situation where a child is in an inferior position of power is one which is likely to also be one where they experience less hope of personally bringing about a quick and successful resolution. Hence, we expected bullied pupils to report higher levels of depression than those who experienced peer-victimization.

As well as negative effects on emotional well-being, we expect bullied pupils to interpret their experience of aggression differently. Appraisals are cognitive interpretations of a situation (Lazarus, 1999) and have been examined in previous bullying research with specific reference to perceptions of threat (the expectation of negative outcomes), challenge (the expectation of positive outcomes) and control (Hunter \& Boyle, 2002, 2004; Hunter, Mora-Merchán, \& Ortega, 2004). Appraisals are related to choice of coping strategy used by victims of bullying, to frequency of bullying and to long-term outcomes of bullying (Hunter \& Boyle, 2002, 2004; Hunter et al., 2004), and so are of interest when examining pupils experiencing aggression. Here, it is expected that bullied children will report lower levels of perceived control and higher levels of threat when compared with pupils 
experiencing peer-victimization, since a more powerful aggressor (e.g. stronger, more popular) is likely to be perceived as less amenable to change and pose a greater threat to physical well-being and social integration.

In terms of the coping strategy used, previous studies have reported positive associations between frequency of victimization/bullying and the use of different strategies such as Social Support Seeking among boys and Internalizing (Andreou, 2001; Bijttebier \& Vertommen, 1998; Hunter \& Boyle, 2004). However, differences between the coping strategies used by bullied and peer-victimized children are likely to rest not on the frequency of bullying (since no difference is necessarily expected in frequency of aggression experienced) but on salient appraisals and attributions (Crick \& Dodge, 1994; Lazarus, 1999), in this case intent and power imbalance. It is reasonable to expect that submissive and/or avoidant behaviours are more likely among victims of bullying, given that they perceive their aggressor to be more powerful. In addition, the presumed higher levels of threat and lower levels of control lead us to expect that bullied students will display more use of emotion-focused strategies (Band \& Weisz, 1988; Bowker, Bukowski, Hymel, \& Sippola, 2000; Hoffner, 1993).

Finally, it is of theoretical interest to examine the potential effect of the type of power imbalance upon well-being, particularly in relation to the gender of the victim. Crick and Grotpeter (1995) suggest that boys and girls use aggression to damage the goals valued by their same-sex peers, namely peer-relationships among girls and physical dominance/instrumentality among boys, and different types of aggression have been shown to have differential outcomes depending upon the gender of the victim (Prinstein, Boergers, \& Vernberg, 2001). The type of power imbalance perceived by children may therefore have different effects according to whether the victim is a boy or a girl, with a physical imbalance having more severe consequences for boys and a popularity imbalance more severe consequences for girls.

\section{Hypotheses}

It was expected that not all pupils experiencing peer-victimization would necessarily report both intent by the aggressor and a power imbalance between themselves and the aggressor. Furthermore, given that bullying appears to be conceptually and theoretically the more serious form of peer-aggression it was expected that bullied pupils would report:

(1) lower levels of perceived control;

(2) higher appraisals of threat;

(3) more use of Wishful Thinking and Social Support coping strategies, but no difference in use of Problem Solving strategies; and

(4) higher levels of depressive symptomatology.

Finally, it is expected that a perceived physical imbalance in power will predict higher levels of appraised threat and depressive symptomatology for boys but not girls, while a popularity imbalance will predict higher levels of appraised threat and depressive symptomatology for girls but not boys.

\section{Method}

\section{Participants}

Participants were 1,429 pupils (50.2\% males and $49.8 \%$ females) aged 8 to 13 years attending mainstream schools in North Lanarkshire or Aberdeenshire, Scotland. Primary 
School pupils were drawn from Primary Five and Primary Six classes in 10 Primary Schools (mean age $=9.37$ years, $S D=0.57$ ). Secondary One and Secondary Two classes were drawn from five Secondary Schools (mean age $=12.45$ years, $S D=0.58$ ). Two of the ten Primary Schools were denominational, while all other schools were nondenominational. Table 1 shows the breakdown of participants by school stage and gender.

Table I. Participants

\begin{tabular}{|c|c|c|c|c|c|c|}
\hline \multirow[b]{3}{*}{ School stage } & \multicolumn{6}{|c|}{ Gender } \\
\hline & \multicolumn{2}{|c|}{ Male } & \multicolumn{2}{|c|}{ Female } & \multicolumn{2}{|c|}{ Total } \\
\hline & $N$ & $\%$ & $\mathrm{~N}$ & $\%$ & $\mathrm{~N}$ & $\%$ \\
\hline P5 & 154 & 47.7 & 169 & 52.3 & 323 & 22.6 \\
\hline P6 & 143 & 58.1 & 103 & 41.9 & 246 & 17.2 \\
\hline SI & 217 & 49.4 & 222 & 50.6 & 439 & 30.7 \\
\hline S2 & 204 & 48.5 & 217 & 51.5 & 421 & 29.5 \\
\hline Total & 718 & 50.2 & 711 & 49.8 & 1429 & 100 \\
\hline
\end{tabular}

\section{Measures}

Peer-victimization and bullying

Children were first presented with a list of aggressive behaviours, specifically Someone called you names, You were threatened by someone, Your belongings were stolen/damaged, You were left out of games or groups, You were bit or kicked, Nasty stories were spread about you, You were forced to do sometbing you did not want to do and Other (please give example) (Hunter, Boyle, \& Warden, 2004b). Accompanying each was a 'tick-box' and the pupils were instructed: Below is a list of ways that people can be nasty or unpleasant to other people. Has anyone been nasty to you, in any of these ways, in the past two weeks? If they have, tick that box and say bow upset you were when it happened.

To measure perceived intent, students were asked Do you think the kid(s) were trying to upset you? (response alternatives were yes, no, don't know). No previous research has examined the effects of different types of power imbalance, so three potentially important types of power imbalance were assessed: physical strength; group size; and popularity. Pupils were asked whether the aggressor(s) was physically stronger, in bigger groups and/or more popular than they were (three separate items, each with yes, or no response alternatives; participants were able to tick as many as applied). No don't know responses were included for the power imbalance items as these were considered to be less subjective perceptions and more reports of 'facts'.

Pupils were then asked how often they had experienced said behaviours (Less than once a week, About once a week, Several times as week, Everyday, Several times everyday). To assess duration, participants were asked how long ago the aggression had started (This week, A few weeks ago, More than a month ago, More than 6 months ago). These questions were used to categorize pupils as non-victims, those experiencing peer-aggression and those experiencing peer-victimization. Pupils were categorized as experiencing peer-victimization if they experienced aggression which was likely to have been repeated in nature; victims of peer-aggression if they had experienced aggression which was likely to have been non-recurring and as non-victims if they reported experiencing no aggression over the past two weeks. They were classified as victims of 
bullying if they met the requirements for peer-victimization, and additionally indicated that (a) their aggressors intended to upset them and (b) there was at least one form of power imbalance between themselves and their aggressor.

\section{Appraisals}

To measure threat appraisal, pupils completed the Hunter et al. (2004b) scale. Pupils were asked When other people are nasty to you, what do you think might happen? followed by four statements (e.g. Your friends won't like you anymore), each of which were rated on a 1 to 4 scale $(1=$ Not likely; $4=$ Very likely $)$. The measure displayed acceptable reliability (Cronbach's $\alpha=.63$ ).

To measure students' control appraisals, they were asked How easy is it for you to stop other people being nasty to you? and responses were again measured on a 1 to 4 scale $(1=$ Very difficult; $4=$ Very easy). Previous research using single-item Likertstyle measures of control has supported the validity of such measures in child and adolescent populations (Causey \& Dubow, 1992; Kliewer, Fearnow, \& Walton, 1998).

\section{Coping strategy use}

Three types of coping strategy were assessed using a shortened version of Hunter's (2000) measure of coping. The original (Hunter, 2000) included three factors (Problem Focused, Seeks Social Support, Wishful Thinking coping), consisting of 29 items but, due to the time constraints imposed by schools, a short-form of the scale was developed.

The items that loaded most highly on each factor were identified and only these were used since they are the best indicators of any given factor (Tabachnick \& Fidell, 1996). Tabachnick and Fidell (1996, p. 677) note that factor loadings over 55 can be considered 'good' and in a confirmatory factor analysis carried out on Hunter's (2000) data, 13 loaded at or above .55. Using these items allowed us to develop a measure approximately half the length of the original (13 items compared to 28 items). Reliability of the short-form was satisfactory: using Hunter's (2000) data, the Social Support (four items: Talked to someone who could do something to belp with the problem, Talked to someone about how you were feeling, Asked someone you look up to for advice, and followed it, Talked to someone to find out more about the problem) and Wishful Thinking (five items: Wished that you could change the way you felt, Wished you could change what happened, Hoped a miracle would happen, Wished you felt better about yourself, Daydreamed or imagined a better place than the one you were in) factors demonstrated good reliability (Cronbach's $\alpha=.79$ and 0.72 , respectively), while the reliability of the Problem Focused factor was adequate (four items: You knew what had to be done, so you tried harder to make things work, Came up with a couple of different solutions to the problem, Changed something so things would turn out alright, Changed or grew as a person in a good way; Cronbach's $\alpha=.67$ ).

Before completing these 13 items in the current study, pupils were told, Below is a list of things you might think about or do when dealing with a problem. Think about when people have been nasty to you in the last two weeks. How did you cope with it? If people were NOT nasty to you in the last two weeks, imagine recent disagreements or arguments you have had with friends or people your age. How did you deal with these problems? The time period 2 weeks was designed to dovetail with the present victimization measure. Pupils were then asked to indicate their use of each coping strategy on a 4-point scale ( $1=$ did not use; $4=$ used very often $)$. 
Depressive symptomatology

Depressive symptomatology was measured using Birleson's (1981) Depression SelfRating Scale (DSRS). The DSRS is an 18-item questionnaire which asks respondents to indicate, using a 3-point scale (never, sometimes, a lot), how often they have felt a variety of different things (e.g. tummy aches, lonely) during the preceding week. One item, I think life isn't worth living was not included in the present study for ethical reasons. Following completion, the child or young person is given a score (out of 34) reflecting their degree of depressive symptomatology. The DSRS has demonstrated good internal reliability and consistency (Birleson, 1981; Oldenburg \& Kerns, 1997), discriminative reliability (in relation to children involved in bullying: Callaghan \& Joseph, 1995) and test-retest reliability (Birleson, 1981). In the current study, internal reliability of the DSRS was good (Cronbach's $\alpha=.77$ ).

\section{Procedure}

Questionnaires were administered to whole classes by the first author in all but one Primary and two Secondary schools who preferred to administer the questionnaires themselves. As the questionnaires were NOT anonymous, all participants were reassured about confidentiality. Following this, the whole questionnaire was read out item by item to the Primary schoolchildren, whereas Secondary schoolchildren were asked to complete the questionnaire with the researcher in the room to answer any question. Instructions were given to those schools carrying out the questionnaire themselves to ensure procedural similarity.

\section{Results}

One-third of the pupils (33.7\%) reported no experience of aggression, $35.6 \%$ reported experiencing peer-aggression (i.e. one-off incidents of aggression) and $30.7 \%$ reported experiencing peer-victimization. Perceptions of intent and power imbalance shown according to the level of aggression reported are shown in Table 2 . It is clear from Table 2 that only a minority of students reported that they were sure that the aggressor did not intend to upset them. Though not shown in Table 2, of the peer-victimized pupils, 34.2\% reported one type of power imbalance, $31.7 \%$ two types and $13.5 \%$ all three types.

The peer-victimization group $(N=438)$ was examined to see how many met the criteria for bullying, that is who perceived an intention on the part of the aggressor to cause upset and the presence of a power imbalance. This resulted in 167 pupils being classified as victims of bullying (38.1\% of all peer-victimized pupils; $11.7 \%$ of the whole sample) with no significant ${ }^{1}$ gender difference. Means and standard deviations on all measures of appraisal, coping strategy use, and depressive symptomatology are shown for both victims of bullying and victims of peer-victimization in Table 3 .

A MANOVA assessed the effects of gender and group membership (bullied or victimized) upon situation appraisal (control, threat), revealing a small but significant multivariate effect of group membership (Pillai's Trace $=0.05, p<.001$; partial$\eta^{2}=.050$ ) but not of gender and there was no interaction. Bullied students perceived significantly more threat $\left(F_{1,434}=17.10, p<.001 ;\right.$ partial- $\left.\eta^{2}=.038\right)$ and significantly

\footnotetext{
'Throughout our results section we refer to statistically significant effects as simply 'significant' to avoid the cumbersome use of language.
} 
Table 2. Perceptions of intent and power imbalance by type of aggression reported

\begin{tabular}{lccc}
\hline Bullying characteristic & Victim's perception & $\begin{array}{c}\text { Peer-aggression victims } \\
(N=509)\end{array}$ & $\begin{array}{c}\text { Peer-victimization victims } \\
(N=438)\end{array}$ \\
\hline Intent & Yes & $23.9 \%$ & $46.2 \%$ \\
& D/K & 48.1 & 40.8 \\
Physically stronger & No & 28.0 & 13.0 \\
& Yes & 40.0 & 51.5 \\
In larger groups & No & 60.0 & 48.5 \\
\multirow{3}{*}{ More popular } & Yes & 38.6 & 49.9 \\
& No & 61.4 & 50.1 \\
& Yes & 35.5 & 46.9 \\
& No & 64.5 & 53.1 \\
\hline
\end{tabular}

Table 3. Means (and standard deviations) for appraisals, coping strategies and depressive symptomatology for bullied and peer-victimized pupils

\begin{tabular}{lcc}
\hline Dependent variable & Peer-victimized pupils & Bullied pupils \\
\hline Wishful thinking & $11.67(4.38)^{* * *}$ & $13.32(4.44)^{* * * *}$ \\
Social support & $8.25(3.52)^{* *}$ & $9.41(3.56)^{* *}$ \\
Problem focused & $8.83(3.01)$ & $8.99(3.18)$ \\
Threat & $1.79(0.72)^{* * *}$ & $2.09(0.77)^{* * * *}$ \\
Control & $2.37(1.05)^{* *}$ & $2.04(1.07)^{* *}$ \\
Depressive symptomatology & $10.16(4.43)^{*}$ & $11.33(5.41)^{*}$
\end{tabular}

$* p<.05 ; * * p<.01 ; * * * p<.001$.

less control $\left(\mathrm{F}_{1,422}=9.34, p=.002\right.$; partial- $\left.\eta^{2}=.022\right)$ than pupils experiencing peervictimization.

A second MANOVA assessed the effects of gender and group membership (bullied children; peer-victimized children) on the three coping strategy measures (Wishful Thinking, Social Support, Problem Focused). There was a small, significant multivariate effect of group (Pillai's Trace $=0.05, p<.001$; partial $-\eta^{2}=.052$ ), indicating that bullied pupils reported more Wishful Thinking $\left(F_{1,388}=19.37, p<.001\right.$; partial$\left.\eta^{2}=.048\right)$ and more Social Support $\left(F_{1,388}=17.89, p<.001 ;\right.$ partial- $\left.\eta^{2}=.044\right)$ than pupils experiencing peer-victimization. A final small, significant multivariate effect was also present for gender (Pillai's Trace $=0.08, p<.001$; partial $-\eta^{2}=.076$ ), indicating that girls reported using significantly more Wishful Thinking $\left(F_{1,388}=12.96, p<.001\right.$; partial- $\left.\eta^{2}=.032\right)$ and Social Support $\left(F_{1,388}=11.17, p=.001\right.$; partial- $\left.\eta^{2}=.028\right)$ than boys, but there was no gender difference for Problem Focused coping.

A two-way between-groups ANOVA assessed the effect of group membership (bullied or victimized) and gender upon depressive symptomatology. This revealed a small significant main effect of group $\left(F_{1,421}=5.99, p=.015\right.$; partial- $\left.\eta^{2}=.014\right)$ with bullied pupils reporting more depressive symptoms than pupils who experienced peervictimization. There was also a small significant main effect of gender $\left(F_{1,421}=7.06\right.$, $p=.008$; partial- $\left.\eta^{2}=.016\right)$ indicating that girls reported more depressive symptoms than boys. The interaction was non-significant.

Our prediction was that a perceived physical imbalance in power would predict higher levels of appraised threat and depressive symptomatology for boys but not girls, 
and that a popularity imbalance would predict higher levels of appraised threat and depressive symptomatology for girls but not boys. Hence, our final analyses, multiple regressions examining the influence of the three types of power imbalance upon threat appraisals and depressive symptomatology, were carried out separately for boys and girls. School-stage (Primary or Secondary) was also included as a predictor variable. These analyses (presented in Table 4) revealed that boys' depressive symptoms were not significantly predicted by any of the variables included. For girls, the predictor variables explained $10.8 \%$ of the variance in depressive symptomatology, with both physical power imbalance and popularity power imbalance significant predictors (presence predicted poorer functioning). When predicting boys' threat appraisals, the predictor variables together explained $7.4 \%$ of the variance in reports, and both physical power imbalance and group-size imbalance were significant individual predictors. For girls, the predictors explained $7.5 \%$ of the variance in threat appraisals, and significant individual predictors were physical power imbalance and popularity power imbalance (again, presence predicting poorer functioning).

Table 4. Results of multiple regression analyses for predicting threat appraisals and depressive symptomatology from school stage and type of power imbalance

\begin{tabular}{|c|c|c|c|c|c|c|c|}
\hline \multirow[b]{2}{*}{ Group } & \multirow[b]{2}{*}{ Predictor } & \multicolumn{3}{|c|}{ Threat } & \multicolumn{3}{|c|}{ Depressive symptoms } \\
\hline & & B & SE B & $\beta$ & B & SE B & $\beta$ \\
\hline \multirow[t]{6}{*}{ Boys } & School stage & 0.45 & .47 & .07 & -0.56 & .79 & -.06 \\
\hline & Physical & -0.90 & .44 & $-.15^{*}$ & -1.32 & .74 & -.14 \\
\hline & Group & -1.08 & .44 & $-.18 *$ & -0.30 & .75 & -.03 \\
\hline & Popularity & -0.01 & .47 & -.02 & -0.44 & .80 & -.05 \\
\hline & & \multicolumn{3}{|c|}{$R^{2}=.074$} & \multicolumn{3}{|c|}{$R^{2}=.026$} \\
\hline & & \multicolumn{3}{|c|}{$F(4,180)=3.50, p<0.01$} & \multicolumn{3}{|c|}{$F(4,176)=1.16, p>0.05$} \\
\hline \multirow[t]{6}{*}{ Girls } & School stage & 0.31 & .41 & .05 & 0.01 & .66 & .01 \\
\hline & Physical & -0.82 & $.4 \mathrm{I}$ & $-.14 *$ & -1.49 & .67 & $-.15^{*}$ \\
\hline & Group & -0.77 & .43 & -.13 & -0.97 & .69 & -.10 \\
\hline & Popularity & -0.94 & .43 & $-.16^{*}$ & -2.35 & .69 & $-.24 * *$ \\
\hline & & \multicolumn{3}{|c|}{$R^{2}=.075$} & \multicolumn{3}{|c|}{$R^{2}=.108$} \\
\hline & & \multicolumn{3}{|c|}{$F(4,201)=3.98, p<0.01$} & \multicolumn{3}{|c|}{$F(4,194)=5.77, p<0.001$} \\
\hline
\end{tabular}

$* p<.05 ; * * p<.01$.

Note. Both significant and non-significant predictors are presented. $R^{2}$-statistic refers to the total amount of variance explained by all the variables entered into the equation above.

\section{Discussion}

The present study indicated that pupils experiencing peer-victimization do not always report characteristics of their situation that would lead us to say they are victims of bullying. Specifically, they do not always report that there exists a power imbalance (in terms of physical strength, group numbers or popularity) between them and their attacker, or that they felt their attacker intended to upset them. Additionally, the two groups of pupils made different threat and control appraisals of the situation, and used different coping strategies. Further, bullied pupils reported more severe depressive symptomatology. Finally, the type of power imbalance experienced by children 
influenced their threat appraisals and levels of depressive symptomatology, and different types of power imbalance were important for boys and girls.

Results indicated that $38.1 \%$ of pupils reporting peer-victimization fitted into our bullied category, and that bullied pupils perceived the situation to be more threatening and less under their control, with both results proving to be independent of gender. This indicates that bullied pupils see their situation as promising more negative outcomes than pupils who are peer-victimized, suggesting it may be (for the victim) the more serious form of peer-aggression. Lower levels of control among bullied pupils might be expected, since their perception of an imbalance of power between themselves and their aggressors may reduce their belief that certain coping strategies will be effective. Adult 'survivors' of childhood bullying report higher levels of concurrent distress when they report that they had low levels of control over their experience of bullying (Hunter et al., 2004). Hence, lower perceptions of control may lead victims of bullying to experience more long-term distress than victims of peer-victimization.

Bullied pupils reported using more Wishful Thinking and Social Support coping strategies, though they did not differ from peer-victimized pupils in their use of Problem Focused strategies. This supported our hypotheses, and suggests that the active strategies used to deal with both of these types of aggression are similar, but that bullying results in greater use of coping strategies focused upon regulating emotional reactions. The specific types of coping strategy used are interesting since Wishful Thinking strategies have been associated with negative psychological outcomes, perhaps due to the ruminative but ultimately ineffectual nature of the cognitions involved (Frydenberg \& Lewis, 2002). In contrast, Social Support has been associated with reductions in subsequent levels of bullying (Smith, Talamelli, Cowie, Naylor, \& Chauhan, 2004). Negative appraisals (high threat, low control) are associated with higher levels of negative emotions such as anger, fear and sadness (Hunter, Boyle, \& Warden, 2006) and therefore it may be that bullied pupils enlist social support to help them deal with these emotions in particular.

Our results indicated that concurrent reports of depressive symptomatology were higher for bullied pupils than for pupils reporting peer-victimization. This could reflect the influence of perceived intent associated with bullying, since this could be expected to increase feelings of persecution and unpopularity. However, the results presented here are cross-sectional and it may also be the case that feelings of depression contribute towards attributions of victimization and persecution.

Intriguing gender differences in the influence of the type of power imbalance were also revealed in the analyses. Viewing an aggressor as more popular or physically more powerful predicted higher levels of perceived threat for girls, whereas, for boys, perceived threat was predicted by physical power imbalance and group-size power imbalance. Thus, different types of power imbalance are perceived to lead to negative outcomes for boys and girls, and it may be the case that a focus on different types of power structure is important when tackling bullying among boys and girls.

Contrary to expectation, levels of depressive symptomatology among male peervictimized pupils were not predicted by any of the three types of power imbalance measured here. As hypothesized, female victims' levels of depressive symptomatology were increased by the perception of an aggressor as more popular, though, unexpectedly, symptoms were also increased when girls perceived aggressors to be physically more powerful. These results for girls reflect the association of perceived power imbalances with threat appraisals, perhaps indicating that bullying carried out by physically stronger or more popular aggressors are particularly problematic for girls, 
and may need specific techniques to tackle them. However, the results in relation to power imbalance and depression for boys were unexpected, and it appears that none of the types of imbalance assessed here accounted for individual differences in male victims' depressive symptomatology. It may be that other types of power imbalance are more important for boys, though it is not immediately clear what these might be.

Establishing that peer-victimization and bullying are distinct from one another has implications for intervention and prevention strategies. Given that bullying appears to be perceived more negatively, it may be important to gauge whether children who report being bullied actually perceive power imbalance and aggressor intent. Students reporting these may require extra help dealing with their emotional reactions to their experience (see also Hunter et al., 2004b). However, more research is needed on the differences between these two overlapping experiences before making concrete suggestions regarding how each should be dealt with. This is particularly true given that the differences reported here were statistically significant, but generally of small effect size.

Although researchers may be interested primarily in either bullying or peervictimization, evidence from this study may provoke more interest in the extent to which these constructs, or pupils' experience of them, are distinct. Hence, the measure that we have developed here, which allows evaluation of both constructs, seems advantageous. Another positive aspect of the current measure, important for those investigating bullying, is that issues of intent and power imbalance are assessed using specific, individual items. This should reduce the extent to which different groups' naïve definitions of bullying impinge upon results (Swain, 1998).

Although these findings do provide several avenues of support for the discriminative validity and conceptual distinctiveness of bullying and peer-victimization, it should be noted that there are weaknesses to the study. First, this study did not measure bullying using the method conventionally employed by researchers, which typically presents a definition of bullying followed by a direct question asking students to report how often they have been bullied 'this term' (e.g. Whitney \& Smith, 1993). Instead, we asked pupils to indicate whether they had experienced specific aggressive behaviours in the preceding 2 weeks, with what frequency and over what duration; they were also asked directly about specific types of power imbalance and aggressor intent. Given that the majority of bullying research has used the conventional method, it would be of interest to conduct a study comparing bullied pupils identified using that method with peer-victimized pupils. Since the method we used identifies students who are either currently experiencing aggression or who have experienced it within a more recent time-frame ( 2 weeks rather than 'this term') than the conventional method, it is possible that the conventional method may result in less pronounced differences between bullied children and those who report peer-victimization. This assumes, of course, that the effects observed here are at their strongest while they are occurring, rather than reflecting a life-events model where maladjustment can be 'triggered' by even brief exposure and yet remain long-term (Kochenderfer-Ladd \& Wardrop, 2001).

Second, power is a multifaceted interpersonal and group dynamic (Cartwright, 1959), and it may be the case that the three types of power imbalance examined here are not sufficient to cover the range of ways in which such an imbalance can exist in interpersonal relationships. For example, power imbalances can exist between different ethnic or socio-economic groups of pupils, between those with and without learning difficulties, or between adolescents who have greater or lesser success in romantic 
relationships. Future research should aim to examine in more detail the types of power imbalance that are present, and most pertinent, in relation to bullying.

Furthermore, the measures used in this study addressed only perceived intent and perceived imbalance of power. This raises the question of whether the bullied and peervictimized children only differed in their social cognitions and attributions regarding their situation, rather than engaging in objectively different social experiences. ${ }^{2}$ It would be valuable to pursue this by examining aggressor intent and power imbalance via strategies other than victims' self-reports. For example, peer-reports, and self-reports from aggressors regarding their intent and feelings of dominance may be illuminating. Another possibility is that the distinction between bullied and peer-victimized children is primarily in the victim's perception or interpretation. In this case, the distinction between bullied and peer-victimized pupils might best be further explored in terms of victim characteristics, for example their self-esteem (with low self-esteem leading to feelings of inferiority and power imbalance), socio-cognitive competencies (e.g. perspective taking, Chalmers \& Townsend, 1990) or social information processing (e.g. hostile attribution biases, Dodge \& Somberg, 1987).

It should also be noted that the measures of threat appraisal and Problem Focused coping both fell below the generally accepted level for internal reliability of scale items (Henson, 2001). Future research should endeavour to develop or use psychometrically stronger scales to assess these constructs, and our results should be interpreted with caution. Psychometrically stronger scales may reveal larger effects between groups since the sensitivity of the measures will be greater.

A final weakness of the present study was the reliance on categorical measures of power imbalance and intent. Such variables may in fact be better conceptualized as continua, making Likert-type scales more appropriate measures. In a related vein, it should be noted that to assess intent we asked children whether or not another child had been trying to upset them, but children may perceive others to be intending physical harm as well as (or less likely, instead of) psychological upset. That is, there may be different relevant aspects of intent which we have not assessed and which may contribute towards sharpening or blurring the differences between bullied and peervictimized children.

Despite these weaknesses, the present study suggests several potentially fruitful avenues for future research to take. The repeated nature of peer-victimization implies that it is likely to be intentional, so why then do so many peer-victimized pupils not perceive intent on the part of their aggressor? It may be that the peer-victimization category included pupils who had experienced repeated aggression which was not 'serious', that is which merely represented playful taunting or 'rough-and-tumble' between friends. A more qualitative investigation of the differences between the two groups may clarify issues such as this. It would also be of interest to find out more about the relationship between bullying and peer-victimization, for example, whether peervictimization is a precursor to bullying, or whether different types of aggression characterize each.

In conclusion, the present research indicates that research on peer-victimization and its effects/correlates cannot be assumed to reflect what would be found in a sample of bullied pupils. The experience of bullying appears to be distinct from, and more negative than, peer-victimization.

\footnotetext{
${ }^{2}$ Footnote removed to retain anonymity of the author(s).
} 


\section{References}

Ahmad, Y., \& Smith, P. K. (1994). Bullying in schools and the issue of sex differences. In J. Archer (Ed.), Male violence (pp. 70-83). London: Routledge.

Andreou, E. (2001). Bully/victim problems and their association with coping behaviour in conflictual peer interactions among school-age children. Educational Psychology, 21(1), 59-66.

Band, E., \& Weisz, J. R. (1988). How to feel better when it feels bad: Children's perspectives on coping with everyday stress. Developmental Psychology, 24(2), 247-253.

Bijttebier, P., \& Vertommen, H. (1998). Coping with peer arguments in school age children with bully/victim problems. British Journal of Educational Psychology, 68, 387-394.

Birleson, P. (1981). The validity of depressive disorder in childhood and the development of a selfrating scale: A research report. Journal of Child Psychology and Psychiatry, 22(1), 73-88.

Bond, L., Carlin, J. B., Thomas, L., Rubin, K., \& Patton, G. (2001). Does bullying cause emotional problems? A prospective study of young teenagers. British Medical Journal, 323, 480-484.

Bowker, A., Bukowski, W. M., Hymel, S., \& Sippola, L. K. (2000). Coping with daily hassles in the peer group during early adolescence: Variations as a function of peer experience. Journal of Research on Adolescence, 10(2), 211-243.

Callaghan, S., \& Joseph, S. (1995). Self-concept and peer victimisation among children. Personality and Individual Differences, 18(1), 161-163.

Cartwright, D. (Ed.), (1959). Studies in social power. Ann Arbor, MI: Institute for Social Research.

Causey, D. L., \& Dubow, E. F. (1992). Development of a self-report coping measure for elementary school children. Journal of Clinical Child Psychology, 21(1), 47-59.

Chalmers, J. B., \& Townsend, M. A. R. (1990). The effects of training in social perspective taking on socially maladjusted girls. Child Development, 61, 178-190.

Champion, K., Vernberg, E., \& Shipman, K. (2003). Nonbullying victims of bullies: Aggression, social skills, and friendship characteristics. Applied Developmental Psychology, 24, 535-551.

Crick, N. R., \& Dodge, K. A. (1994). A review and reformulation of social information-processing mechanisms in children's social adjustment. Psychological Bulletin, 115(1), 74-101.

Crick, N. R., \& Grotpeter, J. K. (1995). Relational aggression, gender and social-psychological adjustment. Child Development, 66, 710-722.

DeRosier, M. E., \& Marcus, S. R. (2005). Building friendships and combating bullying: Effectiveness of S.S.GRIN at one-year follow-up. Journal of Clinical Child and Adolescent Psychology, 34(1), 140-150.

Dodge, K. A., \& Somberg, D. R. (1987). Hostile attributional biases among aggressive boys are exacerbated under conditions of threat to the self. Child Development, 58, 213-224.

Frydenberg, E., \& Lewis, R. (2002). Adolescent well-being: Building young people's resources. In E. Frydenberg (Ed.), Beyond coping: Meeting goals, visions, and challenges (pp. 175-194). New York: OUP.

Lewinsohn, P. M., Roberts, R. E., Seeley, J. R., Rohde, P., Gotlib, I. H., \& Hops, H. (1994). Adolescent psychopathology: II. Psychosocial risk factors for depression. Journal of Abnormal Psychology, 103(2), 302-315.

Hawker, D. S. J., \& Boulton, M. J. (2000a). Subtypes of peer harassment and their correlates: A social dominance perspective. In J. Juvonen \& S. Graham (Eds.), Peer harassment in schools. New York: Guilford.

Hawker, D. S. J., \& Boulton, M. J. (2000b). Twenty years' research on peer victimisation and psychosocial maladjustment: A meta-analytic review of cross-sectional studies. Journal of Child Psychology and Psychiatry, 41(4), 441-455.

Henson, R. K. (2001). Understanding internal consistency reliability estimates: A conceptual primer on coefficient alpha. Measurement and Evaluation in Counseling and Development, 34, 177-189.

Hilsman, R., \& Garber, J. (1995). A test of the cognitive diathesis-stress model of depression in children: Academic stressors, attributional style, perceived competence, and control. Journal of Personality and Social Psychology, 69(2), 370-380.

Hoffner, C. (1993). Children's strategies for coping with stress: Blunting and monitoring. Motivation and Emotion, 17(2), 91-106. 


\section{Simon C. Hunter et al.}

Hunter, S. C. (2000). An examination of victims' responses to bullying, using process theories of appraisal and coping. Unpublished Master's Research thesis, University of Strathclyde, Glasgow.

Hunter, S. C., \& Boyle, J. M. E. (2002). Perceptions of control in the victims of school bullying: The importance of early intervention. Educational Research, 44(4), 323-336.

Hunter, S. C., \& Boyle, J. M. E. (2004). Coping and appraisal in victims of school bullying. British Journal of Educational Psychology, 74(1), 83-107.

Hunter, S. C., Boyle, J. M. E., \& Warden, D. (2004b). Help seeking amongst child and adolescent victims of peer-aggression and bullying: The influence of school-stage, gender, victimisation, appraisal, and emotion. British Journal of Educational Psychology, 74(3), 375-390.

Hunter, S. C., Boyle, J. M. E., \& Warden, D. (2006). Emotion and coping in young victims of peeraggression. In P. Buchwald (Ed.), Stress and anxiety: Application to bealth, community, work place and education (pp. 307-324). Cambridge Scholar Press, Newcastle, UK.

Hunter, S. C., Mora-Merchàn, J. A., \& Ortega, R. (2004). The long-term effects of coping strategy use in the victims of bullying. Spanish Journal of Psychology, 7(1), 3-12.

Kliewer, W., Fearnow, M. D., \& Walton, M. N. (1998). Dispositional, environmental, and contextspecific predictions of children's threat perceptions in everyday stressful situations. Journal of Youth and Adolescence, 27(1), 83-100.

Kochenderfer, B. J., \& Ladd, G. W. (1996). Peer victimization: Cause or consequence of school maladjustment? Child Development, 67, 1305-1317.

Kochenderfer-Ladd, B. J., \& Wardrop, J. L. (2001). Chronicity and instability of children's peer victimisation experiences as predictors of loneliness and social satisfaction trajectories. Child Development, 72(1), 134-151.

Kumpulianen, K., \& Räsänen, E. (2000). Children involved in bullying at elementary school age: Their psychiatric symptoms and deviance in adolescence. An epidemiological study. Child Abuse and Neglect, 24(12), 1567-1577.

Lazarus, R. S. (1999). Stress and emotion: A new synthesis. London: Springer Publishing Company.

Nangle, D. W., Erdley, C. A., Carpenter, E. M., \& Newman, J. E. (2002). Social skills training as a treatment for aggressive children and adolescents: A developmental-clinical integration. Aggression and Violent Behavior, 7, 169-199.

Naylor, P., Cowie, H., Cossins, F., de Bettencourt, R., \& Lemme, F. (2006). Teachers' and pupils' definitions of bullying. British Journal of Educational Psychology, 76, 553-576.

Oldenburg, C. M., \& Kerns, K. A. (1997). Associations between peer-relationships and depressive symptoms: Testing moderator effects of gender and age. Journal of Early Adolescence, 17(3), 319-337.

Olweus, D. (1978). Aggression in the schools. Washington, DC: Hemisphere.

Pellegrini, A. D., \& Long, J. D. (2002). A longitudinal study of bullying, dominance, and victimization during the transition from primary school through secondary school. British Journal of Developmental Psychology, 20, 259-280.

Prinstein, M. J., Boergers, J., \& Vernberg, E. M. (2001). Overt and relational aggression in adolescents: Social-psychological adjustment of aggressors and victims. Journal of Clinical Child Psychology, 30(4), 479-491.

Seals, D., \& Young, J. (2003). Bullying and victimization: Prevalence and relationship to gender, grade level, ethnicity, self-esteem, and depression. Adolescence, 38, 735-747.

Smith, P. K., Talamelli, L., Cowie, H., Naylor, P., \& Chauhan, P. (2004). Profiles of non-victims, escaped victims, continuing victims and new victims of school bullying. British Journal of Educational Psychology, 74(4), 565-582.

Solberg, M. E., \& Olweus, D. (2003). Prevalence estimation of school bullying with the Olweus Bully/Victim questionnaire. Aggressive Behavior, 29(3), 239-268.

Swain, J. (1998). What does bullying really mean? Educational Research, 40(3), 358-364.

Tabachnick, B. G., \& Fidell, L. S. (1996). Using multivariate statistics. USA: HarperCollins.

Whitney, I., \& Smith, P. K. (1993). A survey of the nature and extent of bullying in junior/middle and secondary schools. Educational Research, 35(1), 3-25. 